\title{
Flexibility of Polymers Defined and Related to Dynamic Friction
}

\author{
Witold Brostow ${ }^{1,2}$, Haley E. Hagg Lobland ${ }^{1}$, Hee Jae Hong ${ }^{1}$, Sven Lohse $^{1} \&$ Allison T. Osmanson ${ }^{1}$ \\ ${ }^{1}$ Laboratory of Advanced Polymers \& Optimized Materials (LAPOM), Department of Materials Science and \\ Engineering and Department of Physics, University of North Texas, Denton, USA \\ ${ }^{2}$ College of Mechanics and Robotics, AGH University of Science and Technology, Aleja Adama Mickiewicza, \\ Krakow, Poland \\ Correspondence: Witold Brostow, Laboratory of Advanced Polymers \& Optimized Materials (LAPOM), \\ Department of Materials Science and Engineering and Department of Physics, University of North Texas, 3940 \\ North Elm Street, Denton, TX 76207, USA. E-mail: wkbrostow@gmail.com
}

Received: July 5, 2019

doi:10.5539/jmsr.v8n3p31
Accepted: July 24, 2019

Online Published: July 31, 2019

URL: https://doi.org/10.5539/jmsr.v8n3p31

\begin{abstract}
We have quantitatively defined flexibility of polymers. Flexibility $\mathrm{Y}$ is not an inverse of the brittleness $\mathrm{B}$, rather, the two equations are compared. The expression for flexibility includes the specific volume and the summation of the strengths of chemical bonds-a concept introduced by Linus Pauling. The flexibility is plotted as a function of dynamic friction, resulting in a representative single curve for polymers.
\end{abstract}

Keywords: Polymer Brittleness, Polymer Flexibility, Polymer Dynamic Friction, Strength of Chemical Bonds, Linus Pauling

\section{Scope and Definitions}

Polymers are characterized in terms of a variety of properties, including "brittleness" and "flexibility". Such characterizations help one to choose a polymer for a specific application. For instance, Wang and coworkers (2018) declare that "flexible materials are very attractive because of easy integration into various industrial processes". They have created polymer-containing composite films "feasible to act as self-powered wearable devices by utilizing body's heat or other heat source to generate electricity, wearable temperature sensors, and flexible solid-state coolers, which are very difficult to achieve for inorganic thermoelectric materials since they are intrinsically brittle and rigid". However, in order to better navigate among intrinsic material properties and to find materials with suitable combinations of properties, an equation defining polymer brittleness B has been formulated by two of us and Narkis (Brostow, Hagg Lobland, \& Narkis, 2006), and B has been related to several other properties (Brostow \& Hagg Lobland, 2017). By contrast, there has been no quantitative definition of polymer flexibility, call it $\mathrm{Y}$. We provide such a definition in this paper.

Let us mention a few more examples of the importance of Y. Chinaglia and coworkers (2007) developed much improved light-emitting devices, putting green phosphor compounds in a conductive polymer blend; flexibility is a requirement in such devices. Rubbers and rubber-like materials are known for high flexibilities. Yu and Selvadurai (2007) note that large strains can be achieved in rubbers with little energy dissipation while large deformations of a polyurea elastomer were studied by Amirkhizi and coworkers (2006). Relaxation times of chains in polymers studied through molecular dynamics simulations by Bedrov, Liu and Colby (2008) are important for the polymer properties-and necessarily related to flexibility. Dong-Yu Kim and coworkers (2008) have created organic solar cells on flexible polymeric substrates - with much better mechanical properties than ITO (indium tin oxide) solar cells. Polymer based energy storage devices developed by Nyholm and coworkers at the University of Uppsala (2011) require flexible polymers. Being able to predict and quantify the flexibility of such polymeric materials would improve the ease of development of novel flexible materials as well as create a clear method for comparison of the materials.

As mentioned before, flexibility is not an inverse of brittleness. We first provide a definition of brittleness $B$ (Brostow, Hagg Lobland, \& Narkis, 2006) so as to contrast it with the definition of flexibility later:

$$
B=\frac{1}{E^{\prime} * \varepsilon_{b}}
$$


Here $E^{\prime}$ is the storage modulus determined by dynamic mechanical analysis at the frequency $1.0 \mathrm{~Hz}$ and $\varepsilon_{b}$ is the tensile elongation at break. Thus, the equation for brittleness accounts for both fatigue from repetitive loading as well as the strength associated with a large one-time deformation. Since the time of the original definition, $B$ has become connected to several other mechanical and also tribological properties (Brostow \& Hagg Lobland, 2017). We assume that flexibility is significantly related to the specific volume $\mathrm{V}_{\mathrm{sp}}$. That volume consists of the hard-core volume $\mathrm{V}^{*}$ (the sum of volumes of the individual atoms) and the free volume $\mathrm{V}_{\mathrm{f}}$ (the remaining volume, increasing with the temperature) (Brostow, 2009):

$$
\mathrm{V}_{\mathrm{sp}}=\mathrm{V}^{*}+\mathrm{V}_{\mathrm{f}}
$$

All quantities in Eq. (1) pertain to $1 \mathrm{~g}$. While certain properties might be related to the chain length, our consideration of the volume per $1 \mathrm{~g}$ should eliminate that effect. We also recall the concept and implications of the strength of chemical bonds defined decades ago by Linus Pauling (1932). The stronger are the bonds inside of a polymer segment, the lower the flexibility. We assume that the chemical bonds between segments do not affect $Y$ significantly. We are now ready to define flexibility of polymers as follows:

$$
Y=\frac{V_{s p}}{\sum_{i}^{n} U_{b i}}
$$

Here $V_{s p}$ is the specific volume in $\mathrm{cm}^{3} / \mathrm{g}$ at a given temperature while $\sum_{i}^{n} U_{b i}$ is the sum of the strengths of bonds in the monomer of a given polymer. We have taken into account that the larger $V_{s p}$ is, the more space there is between the chains, thus enabling their movements and reorientation. The summation in the denominator in Eq. (3) follows the ideas of Pauling; clearly strong bonds provide low flexibility. Being able to predict and quantify the flexibility of polymeric materials would improve the ease of development of novel flexible materials as well as create a clear method for comparison of the materials.

Comparing Eqs. (1) and (3) we see that they do not have even one common parameter. In other words, we have not assumed a simple relationship between $\mathrm{Y}$ and B.

\section{Connection to Dynamic Friction}

A definition of a physical property ought to be useful. The capability to calculate some other property from our flexibility would demonstrate usefulness. A large sector of publications on polymers deals with their mechanical properties. This is understandable; if a material breaks into pieces easily, its other properties are irrelevant. However, as concluded in the so-called Jost report commissioned by the Government of the United Kingdom many decades ago (1966), industry and the entire society incur every year large financial losses when machinery parts have to be replaced by identical ones because of wear resulting from friction. For this reason, we focus now on dynamic friction z (often called "coefficient of friction" or "COF"). This parameter is defined as the ratio of the friction force to the applied normal force to maintain a movement at a constant speed. There is also static friction - typically higher and needed to initiate the movement. As discussed by Burris and Sawyer (2009), the definition of $\mathrm{z}$ is disarmingly simple - while there are practical challenges in accurate measurements of this quantity.

While in many situations one aims to achieve low friction values, Majidi and his colleagues (2006) declare: "High-friction, low-adhesion materials are important for applications such as automobile tires and shoes. Since surface roughness limits contact area, soft materials have typically been used to obtain high friction". A group at the University of California Berkeley used friction to determine directional adhesion of arrays of angled microfibers-inspired by geckos (2008). A group at the University of Toronto (2015) has developed composites with high friction on wet ice. Thus, they have created a promising material for ice traction.

In a highly flexible material, we can imagine 'ploughing in' of the probe into the material and the resulting high friction. Consider the polymers widely used in a variety of industries, also in medicine and in food packaging often called engineering polymers. Given those wide uses, reliable data was available. In other words, if for whatever reason somebody would obtain for a widely used polymer a value much different from that reported in the literature, the experiment would be repeated. Still, literature data for each polymer were within a certain range; this applies to both specific volume and dynamic friction. Therefore, these ranges are marked in the Figure below.

We have plotted $\mathrm{Y}$ vs. $\mathrm{z}$ values for those polymers for which extensive and mutually consistent values were available. The results are shown in Figure 1; an evident relationship is demonstrated. The results are well represented by a two-parameter equation:

$$
\mathrm{Y}=0.311 \mathrm{z}^{-0.987}
$$




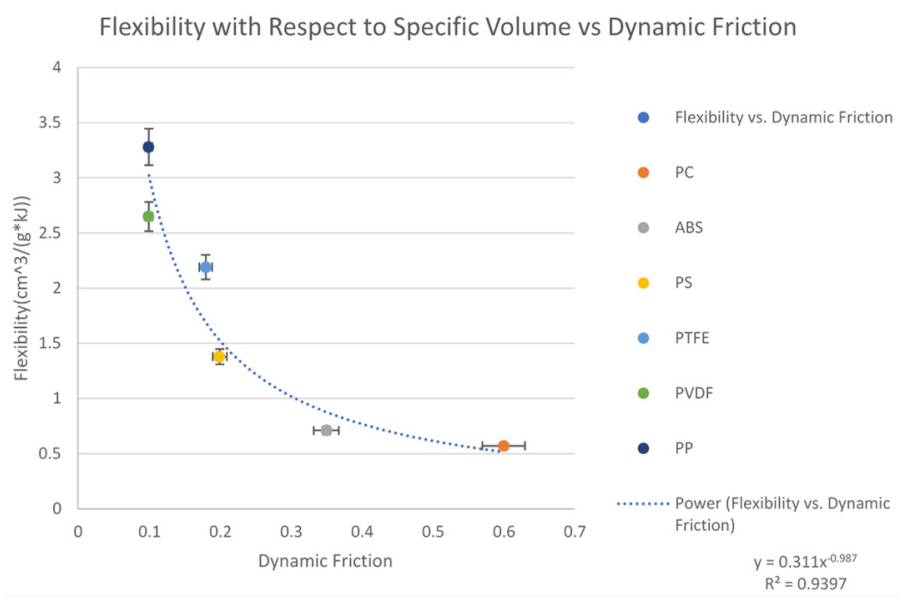

Figure 1. A plot of flexibility $\mathrm{Y}$ versus dynamic friction $\mathrm{z}$ for polymers

We see that polypropylene (PP) has the highest value of flexibility $\mathrm{Y}$ and also the lowest value of dynamic friction. The following one is poly (vinylidene fluoride) (PVDF). The next one is polytetrafluoroethylene (PTFE) - well known under the industry name Teflon ${ }^{\circledR}$ precisely because of low $\mathrm{z}$ and a relative ease of manufacturing. The following ones are polystyrene (PS) and acrylonitrile/butadiene/styrene (ABS), the latter an elastomer copolymer. The last one is polycarbonate (PC).

\section{General Comments}

As mentioned, work on lowering friction and mitigating tracks created by the moving intenter in polymers is pertinent. Such tracks have been studied in some detail (Brostow et al., 2007). Low friction-and low wear related to it - are important also in movable devices in aerospace systems investigated by Voevodin and his colleagues (1999). Different approaches are used to lower polymer dynamic friction, such controlled phase separation developed by Burris, Sawyer and their coworkers in polymer blend thin films (2006). A technique called friction transfer has been developed and applied to deposition of ordered conjugated polymer nanowires and transistor fabrication (Li, Newsome, Russell, Kugler, \& Ishida, 2005). Let us also note pattern-directed self-organization in polymer thin films achieved by Grolman and her colleagues (2017). They point out that "many of nature's surfaces have distinct textures on different surfaces of the same object". Nature creating "brick and mortar" structure in nacre became an inspiration for creating such structures in fiber-reinforced polymer composites (De Luca, Sernicola, Shaffer, \& Bismarck, 2010). Self-limiting layer-by-layer assembly of well aligned inorganic platelets in a polymer provides a coating with an unusually high stress dissipation capability. Addition of carbon nanotubes to polymers (Giri, Das, \& Kalra, 2012) is likely to affect the flexibility. Piezoresistive metal + polymer composites show high stress sensitivity (Kazemian Abyaneh, Ekar, \& Kulkarni, 2010)-which might be related to flexibility. Self-organization was mentioned before-while there is an entire book by Desai and Kapral on self-organized and self-assembled structures (2009).

Polymers in contact with liquid or vapours can undergo swelling - a process important in certain applications (Brostow, 1971; Svagan, Hedenqvist, \& Berglund, 2009). Our z might possibly serve also as a measure of the degree of swelling. Additive manufacturing of polymers becomes more and more used (Dudek and his colleagues, 2017). Evaluation of flexibility necessarily involving several layers so deposited might be a tool for verification of uniformity of the polymers so created.

Our concept of flexibility applies to continuous polymers. While porous polymers and polymer foams are interesting and have important applications (Haibach, Menner, Powell, \& Bismarck, 2006; Kulygin \& Silverstein, 2007; Silverstein, 2014), our definition is not directly applicable to them. An interesting phenomenon is polymorphism - seen in various kinds of materials, from inorganic (Lallancette \& coworkers, 2018) to polymers (Azzurri, Flores, Alfonso, Sics, Hsiao, \& Baltá-Calleja, 2003). Given Eq. (3), it would be interesting to determine changes in flexibility during polymorphic transitions of polymers.

Polymer science has several faces - as shown by Gedde in his book (2001) and by Lucas and her colleagues in their book (2001). While many laboratories are creating valuable experimental data, our philosophy is: by creating relationships between different properties, we save time and effort in experimentation. A needed property can be 
calculated from a different one. Mechanical, thermodynamic and tribological properties of polymers are so considered. The above paper is an example of implementation of this approach. Another example is calculation of the isobaric thermal expansivity of polymers from the brittleness B (Brostow \& Osmanson, 2019).

\section{Acknowledgement}

The contributions of data collection and data analysis made by Taehwan Kim (supported in part by the Encore Wire Corp., McKinney, TX), Varun Nayak and Victoria Shi are gratefully acknowledged. We also appreciate constructive comments of a reviewer of our manuscript.

\section{Conflict of interests}

The authors declare that there is no conflict of interests regarding the publication of this paper.

\section{References}

Amirkhizi, A. V., Isaacs, J., McGee, J., \& Nemat-Nasser, S. (2006). An experimentally-based viscoelastic constitutive model for polyurea, including pressure and temperature effects. Phil. Mag., 86, 5847-5866.

Azzurri, F. A., Flores, A., Alfonso, G. C., Sics, I., Hsiao, B. S., \& Baltá-Calleja, F. J. (2003). Polymorphism of isotactic polybutene-1 as revealed by microindentation hardness. Part II: correlations to microstructure. Polymer, 44, 1641-1645.

Bedrov, D., Liu, W., \& Colby, R. H. (2008). Influence of polymer chain connectivity on local composition distribution in miscible polymer blends. Phil. Mag., 88, 3979-3989.

Brostow, W. (1971). On swelling of natural rubber in organic solvents. Macromolecules, 4, 742.

Brostow, W. (2009). Reliability and prediction of long term performance of polymer-based materials. Pure \& Appl. Chem., 81, 417-432.

Brostow, W., \& Hagg Lobland, H. E. (2017). Materials: Introduction and Applications. John Wiley \& Sons.

Brostow, W., \& Osmanson, A. T. (2019). From mechanics to thermodynamics: A relation between the brittleness and the thermal expansivity for polymers. Mater. Letters $X, 1,100005$.

Brostow, W., Chonkaew, W., Rapoport, L., Soifer, Y., \& Verdyan, A. (2007). Grooves in scratch testing. J. Mater. Res., 22, 2483-2487.

Brostow, W., Hagg Lobland, H. E., \& Narkis, M. (2006). Sliding wear, viscoelasticity and brittleness of polymers. J. Mater. Res., 21, 2422-2428.

Burris, D. L., \& Sawyer, W. G. (2006). A Low Friction and Ultra Low Wear Rate PEEK/PTFE Composite. Wear, $261,410-418$.

Burris, D. L., \& Sawyer, W. G. (2009). Addressing Practical Challenges of Low Friction Coefficient Measurements Tribol. Letters, 35, 17-23.

Chinaglia, D. L., Gozzi, G., Schmidt, T. F., Santos, L. F., Balogh, D. T., Oliveira Jr, O. N., \& Faria, R. M. (2007). Fabrication of novel light-emitting devices based on green-phosphor/conductive-polymer composites. Philosophical magazine letters, 87(6), 403-408.

De Luca, F., Sernicola, G., Shaffer, M. S. P., \& Bismarck, A. (2010). "Brick-and-Mortar" Nanostructured Interphase for Glass-Fiber-Reinforced Polymer Composites. ACS Appl. Mater. Interfaces, 10, 7352-7361.

Desai, R. C., \& Kapral, R. (2009). Dynamics of Self-organized and Self-assembled Structures. Cambridge - New York, Cambridge Univ. Press.

Dudek, P., Rapacz-Kmita, A., Cieslik, J., Stodolak-Zych, E., \& Gajek, M. (2017). Additive manufacturing of thermoplastic matrix composites using Selective Laser Sintering. In A. Rotaru, T. Lupaşcu, \& F. Paladi (Eds.), Central and Eastern European Conference on Thermal Analysis and Calorimetry (pp. 28-31). Chişinău, Book of abstracts, Eds. Academica Greifswald, p. 260; ISBN: 978-3-940237-47-7.

Gedde, U. W. (2001). Polymer Physics. Dordrecht - Boston, Kluver Academic Publishers.

Giri, S., Das, C., \& Kalra, S. (2012). Preparation and Characterization of the Cobalt Doped Polyaniline/MWCNT Nanocomposites for Supercapacitor Application. J. Mater. Sci. Res., 1, 10.

Grolman, D., Bandyopadhyay, D., Al-Enizi, A., Elzatahry, A., \& Karim, A. (2017). Dual Imprinted Polymer Thin Films via Pattern Directed Self-Organization. ACS Appl. Mater. Interfaces, 9, 20928-20937. 
Haibach, K. A., Menner, A., Powell, R., \& Bismarck, A. (2006). Tailoring mechanical properties of highly porous polymer foam: Silica particle reinforced polymer foams via emulsion templating. Polymer, 47, 4513-4519.

Jost, H. P. (1966). Tribology Education and Research: Report on the Present Position and Industry's Needs. HM Stationary Office.

Kazemian Abyaneh, R., Ekar, S., \& Kulkarni, S. (2012). Piezoresistivity and Mechanical Behavior of Metal-polymer Composites under Uniaxial Pressure. J. Mater. Sci. Res., 1, 50.

Kulygin, O., \& Silverstein, M. S. (2007). Porous poly(2-hydroxyethyl methacrylate) hydrogels synthesized within high internal phase emulsions. Soft Matter, 3, 1525-1529.

Lalancette, L. A., Arslan, E., Bernal, I., Wilhelm, D., Grebowicz, J. S., \& Pluta, M. (2018). The thermochemistry and crystallography of the metal tris-acetylacetonates. J. Thermal Anal. \& Calorim., 131, 2809-2819.

Lee, J., Fearing, R. S., \& Kornvopoulos, K. (2008). Directional adhesion of gecko-inspired angled microfiber arrays. Appl. Phys. Letters, 93, 191910.

Li, S. P., Newsome, J. C., Russell, D. M., Kugler, T., \& Ishida, M. (2005). Friction transfer deposition of ordered conjugated polymer nanowires and transistor fabrication. Appl. Phys. Letters, 87, 062101.

Lucas, E. F., Soares, B. G., \& Monteiro, E. (2001). Caracterização de Polimeros (e-papers). Rio de Janeiro.

Na, S. I., Kim, S. S., Jo, J., \& Kim, D. Y. (2008). Efficient and flexible ITO-free organic solar cells using highly conductive polymer anodes. Advanced Materials, 20(21), 4061-4067.

Nyholm, L., Nyström, G., Mihranyan, A., \& Strømme, M. (2011). Toward Flexible Polymer and Paper-Based Energy Storage Devices. Adv. Mater., 23, 3751-3769.

Pauling, L. (1932). The Nature of the Chemical Bond. Cornell University Press, Ithaca, NY.

Rizvi, R., Naguib, R. H., Fernie, G., \& Dutta, T. (2015). High Friction on Ice Provided by Elastomeric Fiber Composites with Textured Surfaces. Appl. Phys. Letters, 106, 111601.

Silverstein, M. S. (2014). Emulsion-templated porous polymers: A retrospective perspective. Polymer, 55, 304-320.

Svagan, A. J., Hedenqvist, M. S., \& Berglund, L. (2009). Reduced water vapour sorption in cellulose nanocomposites with starch matrix. Compos. Sci. Tech., 69, 500-506.

Voevodin, A. A., O’Neill, J. P., \& Zabinski, J. S. (1999). Nanocomposite tribological coatings for aerospace applications. Surf. Coat. Technol., 116-119, 36-45.

Wang, L., Zhang, Z., Liu, Y., Wang, B., Fang, L., Qiu, J., ... \& Wang, S. (2018). Exceptional thermoelectric properties of flexible organic- inorganic hybrids with monodispersed and periodic nanophase. Nature communications, 9(1), 3817.

Wilkinson, M., Autumn, K., \& Fearing, R. S. (2006). High Friction from a Stiff Polymer Using Microfiber Arrays. Phys. Rev. Letters, 97, 076103.

Yu, Q., \& Selvadurai, A. P. S. (2007). Mechanics of a rate-dependent polymer network. Phil. Mag., 87, 3519-3530.

\section{Copyrights}

Copyright for this article is retained by the author(s), with first publication rights granted to the journal.

This is an open-access article distributed under the terms and conditions of the Creative Commons Attribution license (http://creativecommons.org/licenses/by/4.0/). 